\title{
DIVERSITY MANAGEMENT IN THE CONTEXT OF CORPORATE SOCIAL RESPONSIBILITY
}

\author{
Marie Bednarikova $^{\mathbf{1}}$, Jana Kostalova ${ }^{2}$, Jan Vavra ${ }^{3}$, Denisa Halamova ${ }^{4}$ \\ 1, 2, 3,4 Department of Economy and Management of Chemical and Food Industries, \\ Faculty of Chemical Technology, University of Pardubice, Studentska 95, \\ 53201 Pardubice, Czech Republic

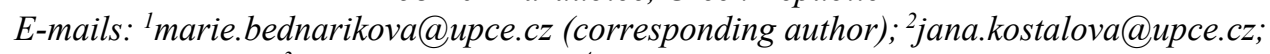 \\ 3jan.vavra@upce.cz; ${ }^{4}$ halamova.denisa@gmail.com
}

\begin{abstract}
During last years there are many new modern attitudes and trends in the field of human resources management. The article is focused to one of these trends - diversity management. The aim of the authors is to evaluate single components of diversity management namely in the context of corporate social responsibility (CSR). In addition different possibilities of application of diversity management in practice as instruments of CSR are submitted to analysis. The end of this article shows the results of research oriented to experience with diversity management put into practice in the selected companies in the Czech Republic.
\end{abstract}

Keywords: diversity management, corporate social responsibility, human resources management, application of diversity management in practice, application of diversity management in Czech firms.

JEL Classification: M14, I31, M12.

\section{Introduction}

Business environment is now changing rapidly. To be able to succeed in the market, companies have to pay their attention not only to their economic activities, but also to all the stakeholders affecting the corporate image. Corporate activities are mostly performed within certain legal and other standards. However, close attention is nowadays also paid to activities companies carry out on a voluntary basis, i.e. beyond their mandatory obligations. These activities represent the concept of so-called corporate social responsibility (CSR). Corporate success depends on the fact how the employees are motivated. Employment is a part of our everyday lives, and our job satisfaction is reflected not only in our job performance, but also in the quality of our personal lives. The social area of CSR refers to employees, employee care, and care for a good working environment and working conditions.

One of the areas of the social CSR is ban on discrimination. It refers to different treatment of persons that are members of different groups. In the Czech Republic, discrimination is forbidden by the Charter of Fundamental Rights and Freedoms, and by the so-called Anti-Discrimination Act, yet it is not possible to say that it does not exist in corporate practice. It is, above all, the problem of unequal position of men and women in the labour market, but it also affects the longterm unemployed, children from socially weak families, bodily handicapped persons, foreigners, persons who have been in conflict with the law, etc.

Present-day work groups are, thanks to opening of the doors to the outside world, very diverse. However, this diversity can be of benefit to the company only if the company is able to manage it. Management of diverse work teams is dealt with by diversity management, which is a superstructure of the area of discrimination and equal opportunities in the social CSR. Diversity is also closely related to the idea of inclusion, which strives for integration of discriminated persons into the predominant group.

The research aims to assess whether selected companies of the chemical industry in the Czech Republic introduce diversity management into their corporate practice, and which parts of diversity management are relevant to Czech companies. 


\section{Literature review}

\subsection{Corporate Social Responsibility (CSR) concept}

Corporate social responsibility includes such corporate activities that do not belong to their mandatory obligations. The scope of the CSR concept has gone through a certain development, and nowadays the number of its areas has stabilized at five. They are economic, social, environmental, ethical, and philanthropic areas (Tetřevová, Vávra, Bednaříková, Munzarová, \& Koštálová, 2017). It is also important to specify towards whom the company should be responsible. Generally, it is possible to say that towards all its stakeholders (Aguilera \& Jackson, 2003), as they largely affect the image the company creates in the eyes of the public, and they are also affected by the company's activities.

The economic area of CSR includes transparency of business activities and development of relationships with the stakeholders. Companies should focus on manufacturing useful products and provision of useful services, their good quality, reasonable prices, and generation of a reasonable profit. Özbilgin and Tatli (2011) point out that there are multiple stakeholders with different and often conflicting interests in the field of equality and diversity. The social area of CSR focuses on employees, their satisfaction, and the environment they work in. Companies should respect the needs and interests of their employees, as they are not able to fulfil their economic targets without them. The environmental CSR represents the effort to minimize negative impacts on the environment. Companies are not only obliged to observe the valid legislation, but they also have to seek new and unconventional ways to preservation of the environment for future generations. The ethical CSR not only appeals to companies to observe ethical norms, but it also encourages them to promote these norms more intensively. The philanthropic CSR concerns corporate volunteering and donorship. A good name of a company is also created through the company's participation in public events, or through support of nonprofit organizations. Philanthropy may refer to a one-time activity, or it may refer to long-term involvement in community activities or projects. Performed activities can be of the physical character, or in the form of assistance or expertise.

\subsection{Social area of CSR}

Each company aims to be successful in the market, to be developing, to build a good reputation, etc. To be able to achieve its targets, a company needs quality, qualified, and mainly also highly motivated employees. It contributes to employee motivation through a system of stimuli. Some stimulation elements are given by the law, e.g. the obligation to provide remuneration for the work done, or to ensure a safe work environment. A company has to make sure that none of the employee groups experiences any form of depreciation or discrimination (Barmes \& Ashtiany, 2003).

If a company deals with the social area of CSR, it certainly affects creativity and increases motivation of the employees. It is possible to say that nowadays one of the major tasks of managerial work is to achieve employee satisfaction, as it is the main road to fulfilment of corporate targets. In the social area of CSR, a company has a number of possibilities of what it can do for its employees beyond its obligations. In addition to the above mentioned safety at work, which is logically at the forefront of interest of each employee and employer, this area also includes care for education, ban on discrimination, ban on forced and child labour, ensuring freedom of association and the right to collective bargaining, employee care, observance of working hours, ensuring accessibility of the workplace, fight against mobbing, ensuring work-life balance, elimination of pestering and sexual harassment in the workplace, or ensuring healthy corporate culture (Bednarikova, Vavra, Munzarova \& Zvolankova, 2017).

Of course, health protection at work is stipulated by law. However, a socially responsible company is aware of the fact that there is not an absolutely safe workplace or absolutely safe work. Therefore, it strives to minimize workplace hazards and harmful effects and to provide its employees with above-standard health care. A socially responsible company introduces knowledge management and invests in education and development of its employees. This investment returns in any event. As for the area of discrimination, the situation is governed by the law, but a socially responsible employer shall never tolerate any discriminating behaviour, and they will investigate and punish any manifestation of such behaviour. The problems of discrimination and equal opportunities does not only refer to men and women, but also to bodily handicapped persons, the long-term unemployed, children from socially-weak families, persons with a criminal record, or foreigners living in our country.

Companies in the Czech Republic are particular about the fact that they do not tolerate any 
forced or child labour and that they make it possible for their employees to protect themselves through association in the trade unions. Socially responsible companies do not tolerate mobbing in the workplace, and they also solve any manifestation of pestering or sexual harassment in the workplace very strictly. What is very trendy nowadays is taking care of work-life balance. Socially responsible employers pay attention to work-life balance of their employees, as their private lives affect their performance at work, and their job satisfaction reflects on their private lives.

Socially responsible behaviour towards employees results in a number of advantages and benefits for both parties. As for employees, it increases their self-confidence and job satisfaction, they tend to suffer from stress less, they are willing to improve their qualifications or to be involved in management of the company, and so their loyalty grows, too. As for the company, it increases efficiency at work, and it thus results in higher financial performance of the company. The company reduces its costs as a result of a lower sick leave rate and a lower number of injuries. It does not have to keep looking for new employees, and subsequently to adapt and train them. What also decreases is the number of disputes in the workplace and employee turnover. A responsible employer is perceived by the public as an attractive employer.

\subsection{Diversity management}

Diversity management was brought to Europe by globalization and demographic situation in the European market at the end of last century. According to Ivancevich and Gilbert (2000), in the 21 st century managers in public and private organizations are searching for and experimenting with various approaches to deal with increasing workforce diversity more effectively. Diversity concepts are based on the natural diversity at a company (Bergen, Soper, \& Foster, 2002; Jonsen, Maznevski, \& Schneider, 2011; Robertson, 2013; Kersten, 2000), which we can encounter in the workplace (Kocianova, 2012; Harrison \& Klein, 2007). Demographic composition of the workforce is changing continuously due to globalization and openness of the labour market (Ashkanasz, Hartel, \& Daus, 2002; Barkema, Baum, \& Mannix, 2002; DiStefano \& Maznevski, 2000). Extraordinary specifics are included in ethnic diversity (Singh \& Point, 2006, Tisserant, Wagner, \& Barth, 2013) and cultural diversity (Stahl, Maznevski, Voigt, \& Jonsen, 2010). Unless diversity in work teams is managed sufficiently, mutual differences might not be understood, and this might result in hidden or even open discrimination.

Diversity management can be approached by the company liberally (creation of rules to ensure equal opportunities and equal treatment), radically (ensuring equal representation of each employee group when filling vacancies in accordance with predetermined quotas), or transformationally (effort for integration of positive procedures when taking liberal and radical approaches). According to Lauring (2013), it is essential to find balance between global integration and local responsiveness.

The variety of work groups from the point of view of diversity management contributes to enrichment of work thanks to different characters, experience, opinions, tolerance, and creativity of employees (Van Knippenberg \& Schippers, 2007). It eliminates discrimination and prejudice and affects creation of the corporate culture. It also strengthens innovation and decreases problems in communication, and it helps to manage conflicts. It also helps to improve the work environment (Chrobot-Mason \& Aramovich, 2013; Ely \& Thomas, 2001; Härtel, 2004; Van Knippenberg, Van Ginkel, \& Homan, 2013).

Diversity can be divided into primary and secondary diversity. Primary diversity includes age (Botek, 2017), ethnicity, sex (gender), sexual orientation, race, and mental and physical abilities (Lorbiecki, 2001). This primary dimension has an impact on the person's ability to find employment. It is clearly visible, and people often focus on it, as they are more sensitive to it. Gender diversity is often discussed in relation to a lower number of women in the top management of companies (Dwyer, Richard, \& Chadwick, 2003). Secondary diversity can be marked as variable. It plays an important role in creation of the person's value orientation, their moral principles, expectations, and experience. It includes the style of communication, education, marital status, parental status, geographical affiliation, socioeconomic status, military experience, commuting to work, teamwork, maternal affiliation, religion, being a smoker/non-smoker, and job experience.

Implementation of diversity management into the corporate practice has a number of fundamental reasons. It leads to a change in the corporate culture and to strengthening of the corporate capital. It increases diversity of the workforce as a result of better composition of representatives of different cultures (Chevrier, 2003; Cummings, 
2004; Jackson, Joshi, \& Erhardt, 2003). This guarantees benefits for the company in the area of human resources (Brickson, 2000), strengthening of the market position and a better image (Muzakova, 2014; Gilbert, Stead, \& Ivancevich, 1999). However, the process of implementation of diversity management may also face a number of obstacles (James \& Wooten, 2001; Lorbiecki \& Jack, 2000; Mannix \& Neale, 2005; Zanoni, Janssens, Benschop, \& Nkomo, 2010), including e.g. insufficient consideration and low tolerance to human differences, prejudice against people coming from a different environment, lack of diverse applicants in scientific, technological and other areas, insufficient diversity in senior positions, categorization of people to certain positions, or focussing on care and development of selected individuals only. Diversity is also limited as a result of recruiting employees from the same sources, or during the process of pre-selection within interviews. When introducing diversity management, the company has to bear in mind that it is necessary to take account of the location and orientation of the company, and to choose the basic aspects of diversity that are possible and desirable at the company accordingly.

\section{Research methodology}

Primary research was based on literature review involving professional publications dealing with corporate social responsibility and diversity management. The literature review was followed by a qualitative survey conducted at five randomly selected chemical companies. This survey dealt with implementation of diversity management. The answers were obtained through directed interviews based on a questioning scenario. The interviews involved HR managers of the selected companies. The data were processed using Microsoft Excel and the data analysis was conducted using descriptive statistics tools.

\section{Results and discussion - diversity management at chemical companies}

HR managers of five randomly selected chemical companies in the Czech Republic commented on the status of application of diversity management within their work teams.

\subsection{Characterization of the companies}

Research into the status of application of diversity management by chemical companies was conducted at companies manufacturing organic and inorganic chemicals, fertilizers, plastics, rubber, and diesel and petrol. All of them were joint-stock companies with more than one thousand employees. As the managers did not want to publish a personalized status of implementation of diversity in their work teams, the companies were marked A, B, C, D, and E, and the outcomes specified in Table 1 do not correspond with the order of the scopes of business mentioned above in this paragraph.

\subsection{Diversity management at chemical companies in the Czech Republic}

The respondents from the chemical companies in the Czech Republic expressed their general opinions on the situation in implementation of diversity management in their corporate practice. The research aimed to identify the knowledge of and attitude to diversity management among HR managers, and whether they are taking steps towards its introduction at their companies. The survey included questions concerning both diversity dimensions, i.e. the primary and the secondary dimension. Two of the five interviewed HR managers were women.

To achieve correct evaluation of the level of implementation of diversity management by the companies, it is necessary to take account of the manufacturing process at a chemical company. A part of the process is controlled and managed remotely, through computers and automated devices. In this case, it is possible to apply diversity within a work team. If manual work is needed, and personal attendance of the staff in the production process is necessary, diversity in respect of sex, or age and education is impossible as a general rule. What also matters is the expertise the given work requires. Diversity can be applied unless it is a problem to train an employee and integrate $\mathrm{him} / \mathrm{her}$ in an existing work team even though he/she does not have education in the required area.

What is typical for the chemical industry is an increased risk - significant health hazard at work. Demands placed on the employee reliability and discretion are also typical, as most products can be abused for criminal activity. This is also a reason why there are practically no employees from the ranks of immigrants from non-European developing countries, e.g. Islamic ethnic groups, at chemical companies. It is possible to consider it as prejudice, but in view of a number of incidents involving migrants to West Europe, companies opt for prevention rather than solving incidents subsequently, i.e. when recruiting employees, 
chemical companies prefer verifiable information about the previous job experience.

The directed interviews discovered that all the companies understand the importance of human resources for their success. They are also aware of the importance of work team diversity and of the benefits it can bring to the company. However, it is only in the case of primary diversity where we can speak about a systematic approach to diversity management in work teams.

The data specified in the Table 1 show that the assessed companies are aware of the term of diversity management, but its implementation in both dimensions is intuitive and chaotic rather than systematic.

Table 1 shows the outcomes of the survey from which it is evident which diversity aspects companies are interested in and which aspects they are not dealing with at the moment.

Table 1. Diversity management areas researched at the selected chemical companies (source: authors)

\begin{tabular}{|c|c|c|c|c|c|c|}
\hline & $\begin{array}{l}\text { Chemical } \\
\text { companies }\end{array}$ & A & B & $\mathrm{C}$ & $\mathrm{D}$ & $\mathrm{E}$ \\
\hline \multirow{6}{*}{ 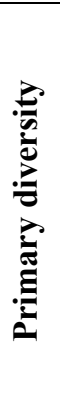 } & Sex (gender) & $\mathrm{Y}$ & $\mathrm{Y}$ & $\mathrm{Y}$ & $\mathrm{Y}$ & $\mathrm{Y}$ \\
\hline & Age & $\mathrm{Y}$ & $\mathrm{Y}$ & $\mathrm{Y}$ & $\mathrm{Y}$ & $\mathrm{Y}$ \\
\hline & Ethnicity & $\mathrm{N}$ & $\mathrm{N}$ & $\mathrm{Y}$ & $\mathrm{N}$ & $\mathrm{Y}$ \\
\hline & Race & $\mathrm{N}$ & $\mathrm{N}$ & $\mathrm{N}$ & $\mathrm{N}$ & $\mathrm{N}$ \\
\hline & $\begin{array}{l}\text { Sexual orienta- } \\
\text { tion }\end{array}$ & $\mathrm{N}$ & $\mathrm{N}$ & $\mathrm{N}$ & $\mathrm{N}$ & $\mathrm{N}$ \\
\hline & $\begin{array}{l}\text { Mental and } \\
\text { physical abili- } \\
\text { ties }\end{array}$ & Y & $\mathrm{Y}$ & $\mathrm{Y}$ & $\mathrm{Y}$ & $\mathrm{Y}$ \\
\hline \multirow{12}{*}{ 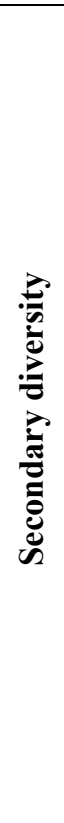 } & Education & $\mathrm{N}$ & $\mathrm{N}$ & $\mathrm{N}$ & $\mathrm{N}$ & $\mathrm{N}$ \\
\hline & Teamwork & $\mathrm{N}$ & $\mathrm{N}$ & $\mathrm{N}$ & $\mathrm{N}$ & $\mathrm{N}$ \\
\hline & Religion & $\mathrm{N}$ & $\mathrm{N}$ & $\mathrm{N}$ & $\mathrm{N}$ & $\mathrm{N}$ \\
\hline & Parental status & $\mathrm{N}$ & $\mathrm{Y}$ & $\mathrm{Y}$ & $\mathrm{N}$ & $\mathrm{N}$ \\
\hline & Marital status & $\mathrm{N}$ & $\mathrm{N}$ & $\mathrm{N}$ & $\mathrm{N}$ & $\mathrm{N}$ \\
\hline & $\begin{array}{l}\text { Socioeconomic } \\
\text { status }\end{array}$ & $\mathrm{N}$ & $\mathrm{N}$ & $\mathrm{N}$ & $\mathrm{N}$ & $\mathrm{N}$ \\
\hline & $\begin{array}{l}\text { Communication } \\
\text { style }\end{array}$ & $\mathrm{N}$ & $\mathrm{N}$ & $\mathrm{N}$ & $\mathrm{N}$ & $\mathrm{N}$ \\
\hline & $\begin{array}{l}\text { Geographical } \\
\text { affiliation }\end{array}$ & $\mathrm{N}$ & $\mathrm{N}$ & $\mathrm{N}$ & $\mathrm{N}$ & $\mathrm{N}$ \\
\hline & $\begin{array}{l}\text { Military experi- } \\
\text { ence }\end{array}$ & $\mathrm{N}$ & $\mathrm{N}$ & $\mathrm{N}$ & $\mathrm{N}$ & $\mathrm{N}$ \\
\hline & $\begin{array}{l}\text { Commuting to } \\
\text { work }\end{array}$ & $\mathrm{N}$ & $\mathrm{Y}$ & Y & $\mathrm{N}$ & $\mathrm{N}$ \\
\hline & $\begin{array}{l}\text { Smoker/Non- } \\
\text { smoker }\end{array}$ & $\mathrm{N}$ & $\mathrm{N}$ & $\mathrm{N}$ & $\mathrm{N}$ & $\mathrm{N}$ \\
\hline & Job experience & $\mathrm{Y}$ & $\mathrm{Y}$ & $\mathrm{Y}$ & $\mathrm{N}$ & $\mathrm{N}$ \\
\hline
\end{tabular}

$\mathrm{N}$ - not implemented

$\mathrm{Y}$ - implemented
As for the employees' sex, there is a valid antidiscrimination act in the Czech Republic, and so open discrimination is not acceptable. As for women, there is sometimes a certain lack of confidence in their abilities, but this is not the case at the surveyed companies. All the five companies can see a large benefit in mixed teams from the point of view of sex, and if it is within the limits stipulated by the Labour Code, it is not important whether an employee is a man or a woman. Femininity enriches a work team with its intuition, thoroughness, and a detached view, which is a counterweight to the men's rather realistic perspective.

The second primary diversity dimension we identified at all the visited companies is the employees' age. All the companies state that it is highly desirable to have mixed-age teams. Nowadays, new recruits are members of so-called Generation Y, who have a completely different approach to work, their lives, and different ideas about their future. At the same time, they have extensive knowledge of and experience with information and communication technologies. Generation $\mathrm{X}$, who are reaching the height of their careers or whose careers are already on the decline, have to cope with this new approach. However, their life and job experience is a priceless source of inspiration for the incoming generation. The difference in the approach will certainly further deepen with arrival of the next generation - Generation Z, for whom it is typical that information and communication technologies are a fully integrated part of their lives. The problem of employing members of different ethnic groups was only identified through the survey conducted at companies $\mathrm{C}$ and $\mathrm{E}$, where there is a higher percentage of employed foreigners, and also those from so-called high-risk ethnic groups, e.g. the Romany, or also employees from orthodox cultures. Race diversity is not dealt with by the given companies.

None of the surveyed companies deal with the problem of diversity for the reason of sexual orientation. HR managers declared that there are sometimes dialogues with the employees on this matter. However, these dialogues are initiated by the employees, and they are rather individual consultations or asking for help. The same situation is in the secondary dimension of diversity, i.e. religion. It is not currently a part of diversity management, either.

The third area of diversity, which is dealt with by all the companies, is the problem of mental and physical abilities of employees. None of the companies employ a mentally handicapped 
person. This is given by the character of manufacturing and by the demands placed on safety at work. However, all the companies employ a certain percentage of bodily handicapped people. The fact that a company employs bodily handicapped people increases attractiveness of the company as an employer. It makes it possible for these people to integrate into the society and the working process, and the employer can benefit from a group of very hardworking and loyal employees.

Individual areas of the secondary diversity are dealt with rather randomly, based on a particular situation. None of the researched companies deal with education, communication style, and teamwork as a diversity problem, as the vacancies are filled on the basis of the requirements of the given job only. However, companies A, B, and $\mathrm{C}$ declare that if there are more applicants for a given job, they take account of the scope of their job experience. When creating work teams, none of the companies take account of any other items of the secondary diversity dimension - marital status, economic status or geographical affiliation. Companies $\mathrm{B}$ and $\mathrm{C}$ are interested in the parental status, as it is very difficult to substitute those team members who have to look after small children. However, this interest does not affect acceptance or non-acceptance of the applicant. It is only a piece of information for the company helping to ensure continuous production, e.g. through an on-call duty of the colleagues. The same situation is at companies $\mathrm{B}$ and $\mathrm{C}$ in the dimension of commuting to work. They also solve the increased risk of late arrivals through an on-call duty of the colleagues.

The surveyed companies do not deal with diversity in terms of the fact whether the employees are smokers or non-smokers. If there are any smokers in a workplace, there are smoking zones reserved for them, and they have to work overtime to make up for the time they spend in the smoking zone. Smoking is strictly forbidden in the workplaces in chemical companies, as it is necessary to ensure safety and health protection at work. Also, none of the companies deal with the problem of military experience, as a large number of employees that have been working in the Czech Republic for less than 20 years have not experienced the compulsory military service.

All the surveyed companies claim allegiance to the idea of CSR, and they present themselves as socially responsible companies. However, they perceive diversity management as a separate issue rather than as an integral part of CSR.

\section{Recommendations}

On the basis of the findings of the survey conducted at the researched chemical companies, we can declare that introduction of diversity management in all its aspects in both diversity dimensions is at a relatively low level. To improve this situation, it is possible to recommend that the companies:

- define dimensions and individual aspects of diversity that are suitable for implementation within the companies with respect to their manufacturing focus and the targets and strategies the company fulfils,

- analyze employee composition in their work teams thoroughly,

- ensure education in the area of diversity management for senior executives and HR managers,

- organize teambuilding events for their employees dealing with the importance and benefits of diversity in work teams,

- do not pre-exclude the possibility of creating diverse teams during the selection procedure by selecting still the same types of employees in accordance with established stereotypes,

- try to differentiate the best candidate from the most suitable one,

- focus not only on the gender and age, but also on other diversity aspects,

- explain the harmful effects of ethnocentrism at work to their employees,

- inform their employees about the advantages of integrating employees of different races or ethnicities into work teams,

- avoid discrimination of an employee or a job applicant (either in an open or a hidden manner) for the reason of their marital status or their parental status,

- implement diversity management as a part of corporate CSR,

- present positive impacts of diversity management to their employees, top management, and also outside the company, e.g. to the public.

A prerequisite for implementation of diversity management at a company is a systematic approach to job applicants from the point of view of diversity and strict building of diverse work teams everywhere where it is possible and suitable. 


\section{Conclusions}

Diversity management may significantly contribute to the corporate success in the market and to the corporate competitiveness in a similar way to the entire CSR concept. However, it means far more work with human resources. It is not possible to focus only on the usual elements of diversity, such as sex and age, but it is also necessary to examine the potential workforce from other points of view. At the same time, companies have to take account of the specifics of their business area.

The research outcomes present the situation in the area of introducing diversity at five selected chemical companies. All the selected companies are comparable in terms of size and style of work, and so it is possible to conclude that the situation is similar at similar companies in the given area in the Czech Republic.

The Czech Republic generally pays relatively a great deal of attention to diversity of work teams in terms of the male to female ratio. As for psychological equipment or intellectual abilities, there are practically no differences between men and women. However, this does not mean that they are identical in terms of their working styles. In spite of that, we can often encounter gender discrimination.

What is even worse is the situation in the area of age diversity. The incoming aggressive, flexible, and self-confident generation crushes older job applicants. In view of the extending life expectancy and the relating possibility of postponing the retirement age, the situation is very serious. There is a generation of 50-year-olds, who have keep on working for another 10-15 years, but the demand for them in the labour market is not very high. It is necessary for the companies to realize that life experience, willingness to work, and loyalty to the employer are very valuable, and it is inevitable for the corporate success to have age-diverse teams, where older employees enrich the younger ones with their experience, and the younger ones help to introduce new technologies.

The term of diversity management is not unknown at the researched companies. However, its implementation into the corporate practice is still in the beginning. Diverse work teams are a result of coincidence rather than a result of systematic work of HR officers and managers within recruitment and selection of employees. Nevertheless, the conducted directed interviews woke up con- siderable interest of HR managers in these problems, and it is almost certain that they will engage in building diverse team much more in the future.

\section{Acknowledgements}

This paper is an outcome of research project: SGS_2018_003 “Moderní postupy v oblastech environmentálního inženýrství a hodnotového managementu", funded by the University of Pardubice, led by prof. Ing. Petr Mikulášek, CSc.

\section{References}

Aguilera, R. V., \& Jackson, G. (2003). The cross-national diversity of corporate governance: dimensions and determinants. Academy of Management Review, 28: 447465. https://doi.org/10.2139/ssrn. 1766002

Ashkanasz, N. M., Hartel, C. E. J., Daus, C. S. (2002). Diversity and emotion: the new frontiers in organizational behaviour research. Journal of Management, 28(3), 307-338. https://doi.org/10.1177/014920630202800304

Barkema, H. G., Baum, J. A. C., \& Mannix, E. A. (2002). Management Challenges in a New Time. Academy of Management Journal, 45(5), 916-930. https://doi.org/10.2307/3069322

Barmes, L., \& Ashtiany, S. (2003). The diversity approach to achieving equality: potential and pitfalls. The Industrial Law Journal, 32, 274-296. https://doi.org/10.1093/ilj/32.4.274

Bednarikova, M., Vavra, J., Munzarova, S., \& Zvolankova, V. (2017, August). The social area of corporate social responsibility and its concept in chemical enterprises as a part of their social welfare. ${ }^{4 s t}$ International Multudisciplinary Scientific Conferences on Social Sciences and Arts SGEM 2017. Albena, Bulgaria.

Bergen, C. W. V., Soper, B., \& Foster, T. (2002). unintended negative effects of diversity management. Public Personnel Management, 31, 239-251.

https://doi.org/10.1177/009102600203100209

Brickson, S. (2000). The impact of identity orientation on individual and organizational outcomes in demographically diverse settings. Academy of Management Review, 25, 82-101.

https://doi.org/10.5465/amr.2000.2791604

Botek, M. (2017, April). Economical aspects of population aging. $5^{\text {th }}$ International Conference on Chemical Technology. Mikulov, Czech Republic.

Chevrier, S. (2003). Cross-cultural management in multinational project groups. Journal of World Business, 38, 141-149.

https://doi.org/10.1016/s1090-9516(03)00007-5

Chrobot-Mason, D., \& Aramovich, N. P. (2013). The psychological benefits of creating an affirming climate for workplace diversity. Group \& Organization Management, 38(6), 659-689.

https://doi.org/10.1177/1059601113509835

Cummings, J. N. (2004). Work groups, structural diversity and knowledge sharing in a global organization. Management Science, 50, 352-364.

https://doi.org/10.1287/mnsc. 1030.0134 
DiStefano, J. J., \& Maznevski, M. L. (2000). Creating value with diverse teams in global management. Organizational Cynamics, 29(1), 45-63. https://doi.org/10.1016/s0090-2616(00)00012-7

Dwyer, S., Richard, O. C., \& Chadwick, K. (2003). gender diversity in management and firm performance: the influence of growth orientation and organizational culture. Journal of Business Research, 56(12), 1009-1019. https://doi.org/10.1016/s0148-2963(01)00329-0

Ely, R. J., \& Thomas, D. A. (2001). Cultural diversity at work: the effects of diversity perspectives on work group processes and outcomes. Administrative Science Quarterly, 46(2), 229-273. https://doi.org/10.2307/2667087

Gilbert, J. A., Stead, B. A., \& Ivancevich, J. M. (1999). Diversity management: a new organizational paradigm. Journal of Business Ethics, 21, 61-76.

Harrison, D. A., \& Klein, K. J. (2007). What's the difference? Diversity constructs as separation, variety, or disparity in organizations. Academy of Management Review, 32(4), 1199-1228.

https://doi.org/10.5465/amr.2007.26586096

Härtel, C. E. J. (2004). Towards a multicultural world: identifying work systems, practices and employee attitudes that embrace diversity. Australian Journal of Management, 29, 189-202. https://doi.org/10.1177/031289620402900203

Ivancevich, J. M., \& Gilbert, J. A. (2000). Diversity management time for new approach. Public Personnel Management, 29, 75-92.

https://doi.org/10.1177/009102600002900106

Jackson, S. E., Joshi, A., \& Erhardt, N. I. (2003). Recent research on team and organizational diversity: SWOT analysis and implications. Journal of Management, 29(6), 801-830.

https://doi.org/10.1016/s0149-2063_03_00080-1

James, E. H., \& Wooten, L. P. (2001). Managing diversity. Executive Excellence, August, 17-18.

Jonsen, K., Maznevski, M. L., \& Schneider, S. C. (2011). Diversity and its not so diverse literature. International Journal of Cross Cultural Management, 11(1), 35-62.

Kersten, A. (2000). Diversity management. Journal of Organizational Change Management, 13, 235-248. https://doi.org/10.1108/09534810010330887

Kocianova, R. (2012). Personnel management - starting points and development (2nd ed.). Praha: Grada Publishing.

Lauring, J. (2013). International diversity management: global ideals and local responses. British Journal of Management, 24(2), 211-224. https://doi.org/10.1111/j.1467-8551.2011.00798.x

Lorbiecki, A. (2001). Changing views on diversity management: the rise of learning perspective and the need of recognise social and political contradictions. Management Learning, 32(3), 345-361.

https://doi.org/10.1177/1350507601323004

Lorbiecki, A., \& Jack, G. (2000). Critical turns in the evolution of diversity management. British Journal of Management, 11(1), 17-31. https://doi.org/10.1111/1467-8551.11.s1.3

Mannix, E., \& Neale, M. A. (2005). What differences make a difference?. Psychological Science in the Public Interest, 6(2), 31-55. https://doi.org/10.1111/j.1529-1006.2005.00022.x

Muzakova, K. (2014). Diversity management - one of key factors for success of manager activities in present global and turbulently changing environment (1st ed.). Ostrava: Key Publishing.

Özbilgin, M., \& Tatli, A. (2011). Mapping out the field of equality and diversity: rise of individualism and voluntarism. Human Relations, 64(9), 1229-1253. https://doi.org/10.1177/0018726711413620

Robertson, Q. (2013). Handbook of diversity management (1st ed.). New York: Oxford University Press.

Singh, V., \& Point, S. (2006). (Re)presentations of gender and ethnicity in diversity stetements on European company websites. Journal of Business Ethics, 68(4), 363379. https://doi.org/10.1007/s10551-006-9028-2

Stahl, G. K., Maznevski, M. L., Voigt, A., \& Jonsen, K. (2009). Unraveling the effects of cultural diversity in teams: a meta-analysis of research on multicultural work groups. Journal of International Business Studies, 41(4), 690-709. https://doi.org/10.1057/jibs.2009.85

Tetřevová, L., Vávra, J., Bednaříková, M., Munzarová, S., \& Koštálová, J. (2017). Corporate social responsibility in socially sensitive branch (1st ed.). Praha: Grada Publishing.

Tisserant, P., Wagner, A. L., \& Barth, I. (2013). The propensity to discriminate: a diagnostic indicator for diversity management. Equality, Diversity \& Inclusion, 32(1), 36-48. https://doi.org/10.1108/02610151311305605

Van Knippenberg, D., \& Schippers, M. C. (2007). Work group diversity. Annual Review of Psychology, 58(1), 515-541.

https://doi.org/10.1146/annurev.psych.58.110405.085546

Van Knippenberg, D., Van Ginkel, W. P., Homan, A. C. (2013). Diversity mindsets and the performance of diverse teams. Organizational Behavior \& Human Decision Process, 121(2), 183-193. https://doi.org/10.1016/j.obhdp.2013.03.003

Zanoni, P., Janssens, M., Benschop, Y., \& Nkomo, S. (2010). Guest Editorial: Unpacking diversity, grasping inequality: rethinking difference through critical perspectives. Organization, 17(1), 9-29. https://doi.org/10.1177/1350508409350344 